\title{
Electric Vehicle Communications Standards Testing and Validation - Phase II: SAE J2931/1
}

R Pratt

K Gowri

December 2012

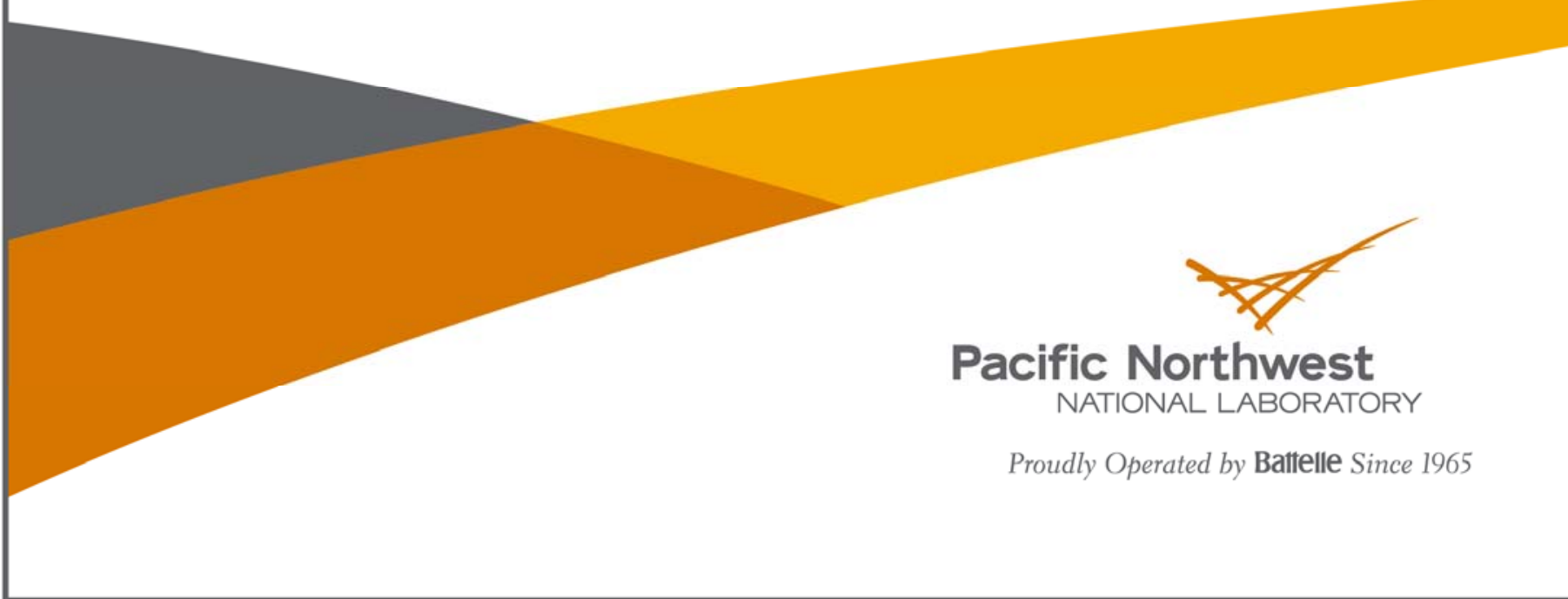




\title{
DISCLAIMER
}

This report was prepared as an account of work sponsored by an agency of the United States Government. Neither the United States Government nor any agency thereof, nor Battelle Memorial Institute, nor any of their employees, makes any warranty, express or implied, or assumes any legal liability or responsibility for the accuracy, completeness, or usefulness of any information, apparatus, product, or process disclosed, or represents that its use would not infringe privately owned rights. Reference herein to any specific commercial product, process, or service by trade name, trademark, manufacturer, or otherwise does not necessarily constitute or imply its endorsement, recommendation, or favoring by the United States Government or any agency thereof, or Battelle Memorial Institute. The views and opinions of authors expressed herein do not necessarily state or reflect those of the United States Government or any agency thereof.

\author{
PACIFIC NORTHWEST NATIONAL LABORATORY \\ operated by \\ BATTELLE \\ for the \\ UNITED STATES DEPARTMENT OF ENERGY \\ under Contract DE-AC05-76RL01830
}

Printed in the United States of America

\author{
Available to DOE and DOE contractors from the Office of Scientific and Technical \\ Information, \\ P.O. Box 62, Oak Ridge, TN 37831-0062; ph: (865) 576-8401 fax: (865) 576-5728 email: \\ reports@adonis.osti.gov
}

\begin{abstract}
Available to the public from the National Technical Information Service, U.S. Department of Commerce, 5285 Port Royal Rd., Springfield, VA 22161 ph: (800) 553-6847 fax: (703) 605-6900

email: orders@ntis.fedworld.gov online ordering: http://www.ntis.gov/ordering.htm
\end{abstract}

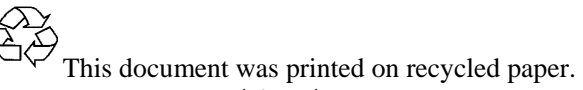




\section{Electric Vehicle Communications Standards Testing and Validation - Phase II: J2931/1}

R Pratt

K Gowri

December 2012

Prepared for

the U. S. Department of Energy

under Contract DE-AC05-76RL01830

Pacific Northwest National Laboratory

Richland, Washington 99352 


\section{Executive Summary}

Vehicle to grid communication standards enable interoperability among vehicles, charging stations and utility providers and provide the capability to implement charge management. Several standards initiatives by the Society of Automobile Engineers (SAE), International Standards Organization and International Electrotechnical Commission (ISO/IEC), and ZigBee/HomePlug Alliance are developing requirements for communication messages and protocols. Recent work by the Electric Power Research Institute (EPRI), in collaboration with SAE and automobile manufacturers, has identified vehicle to grid communication performance requirements and developed a test plan as part of SAE J2931/1 committee work. This laboratory test plan was approved by the SAE J2931/1 committee and included test configurations, test methods, and performance requirements to verify reliability, robustness, repeatability, maximum communication distance, and authentication features of power line carrier (PLC) communication modules at the internet protocol layer level. The goal of the testing effort was to select a communication technology that would enable automobile manufacturers to begin the development and implementation process.

The EPRI/Argonne National Laboratory (ANL)/Pacific Northwest National Laboratory (PNNL) testing teams divided the testing so that results for each test could be presented by two teams, performing the tests independently. The PNNL team performed narrowband PLC testing including the Texas Instruments (TI) Concerto, Ariane Controls AC-CPM1, and the MAXIM Tahoe 2 evaluation boards. The scope of testing was limited to measuring the vendor systems communication performance between Electric Vehicle Support Equipment (EVSE) and plug-in electric vehicles (PEV). The testing scope did not address PEV's CAN bus to PLC or PLC to EVSE (Wi-Fi, cellular, PLC Mains, etc.) communication integration. In particular, no evaluation was performed to delineate the effort needed to translate the IPv6/SEP2.0 messages to PEV's CAN bus.

The J2931/1 laboratory test results were presented to the SAE membership on March 20-22, 2012. The SAE committee decided to select HomePlug GreenPHY (HPGP) as the communication technology to use between the PEV and EVSE. No technology completely met all performance requirements. Both the MAXIM Tahoe 2 and TI Concerto met the 100Kbps throughput requirement, are estimated to meet the latency measurement performance, and met the control pilot impairment requirements. But HPGP demonstrated the potential to provide a data throughput rate of 10x of the requirement and either met or showed the potential to meet the other requirements with further development. 


\section{Acronyms}

AC

AMI

ANL

BER

DOE

DUT

EPRI

EMC

EUMD

EV

EVSE

FSK

GITT

GUI

HAN

HPGP

HMI

IP

MAC

OEM

OFDM

OSI

PNNL

PEV

PHY

PLC

PWM

$\mathrm{RD}$

SPI

SAE

TI

TOU

V2G
Alternating Current

Advanced Metering Infrastructure

Argonne National Laboratory

bit error rate

Department of Energy

Device Under Test

Electric Power Research Institute

Electro Magnetic Compatibility

End-Use-Measurement-Device

Electric Vehicle

Electric Vehicle Support Equipment

Frequency Shift Keying

Grid Interaction Tech Team

Graphical User Input

Home Area Network

HomePlug GreenPHY

Human Machine Interface

Network Layer of the OSI Model

Media Access Control address (Link Layer of OSI Model)

Original Equipment Manufacturer

Orthogonal Frequency Division Multiplexing

Open Systems Interconnection (communications system abstraction layers)

Pacific Northwest National Laboratory

plug-in electric vehicle

Physical Layer of the OSI model

Power line carrier

Pulse Width Modulated

Requirements Document

Serial peripheral interface

Society of Automotive Engineers

Texas Instruments

Time-Of-Use

vehicle to utility grid 


\section{Acknowledgement}

The authors wish to thank Mr. Tim Godfrey, Satish Rajagopalan, Daniel Foster, Arindam Maitra, and John Halliwell of the Electric Power Research Institute (EPRI); Jason Harper and Ted Bohn of Argonne National Laboratory (ANL); Jean-Pierre Fournier and Bogdan Baraboi of Ariane Controls; Matthew Webster, Ed Mullins, and Don Shaver of Texas Instruments; and Jim LeClare, Konrad Scheuer and Kaveh Razazian of MAXIM for providing the evaluation kits and assistance during communication module development and testing.

The authors would also like to thank Mr. Lee Slezak of the U.S. Department of Energy (DOE), Office of Energy Efficiency and Renewable Energy, Vehicle Technologies Program and Mr. Dan Ton of the DOE, Office of Electricity Delivery and Energy Reliability for funding this work. 


\section{Contents}

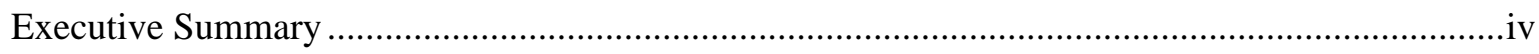

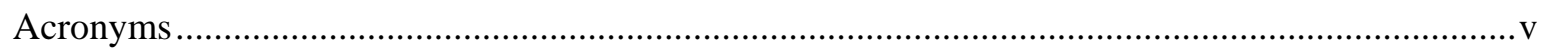

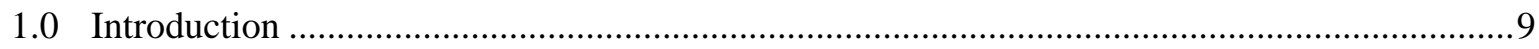

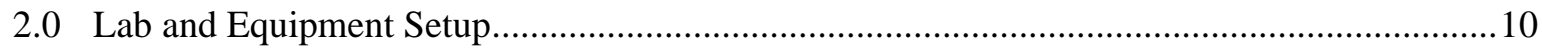

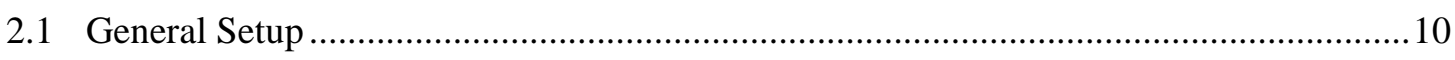

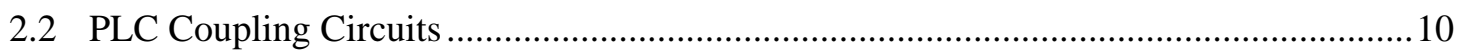

2.3 Control Pilot Measurement Points ................................................................................

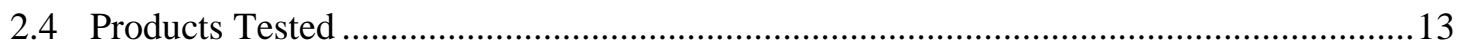

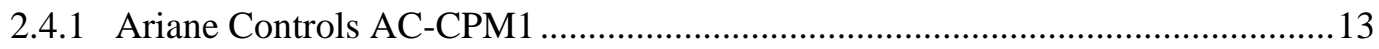

2.4.2 Texas Instrument Concerto ................................................................................. 13

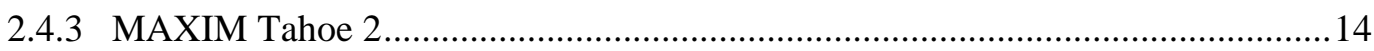

3.0 Bandwidth and Latency Test Procedures .........................................................................15

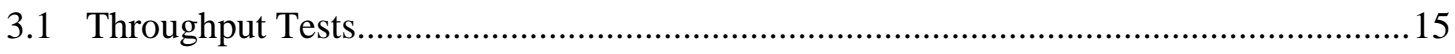

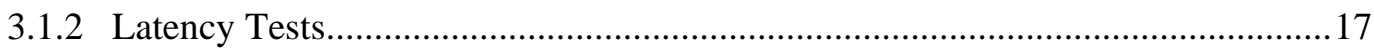

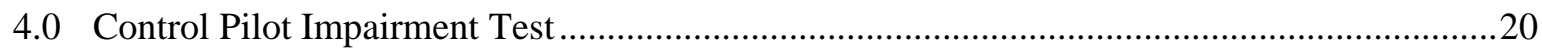

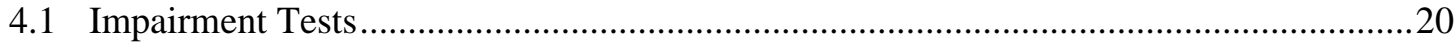

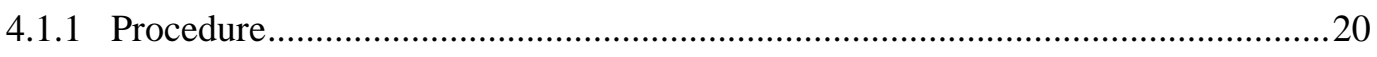

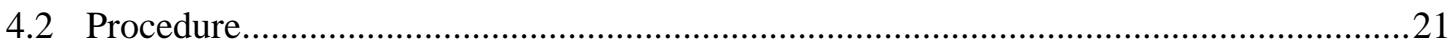

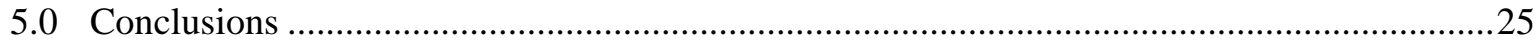

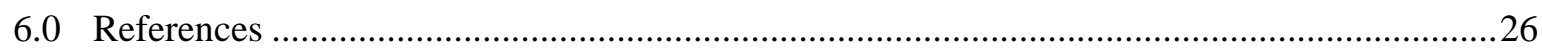




\section{List of Figures}

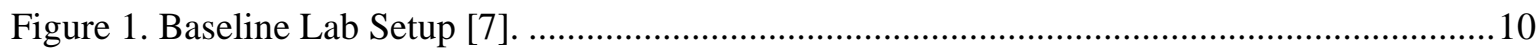

Figure 2. G3 to Pilot Coupling Circuit [7] ............................................................................11

Figure 3. EVSE Pilot Measurement Point [7] .........................................................................11

Figure 4. PEV Pilot Measurement Point [7] .............................................................................. 12

Figure 5. Ariane Controls AC-CPM1 PLC Evaluation Board.....................................................13

Figure 6. Texas Instruments Concerto PLC Module. ..................................................................14

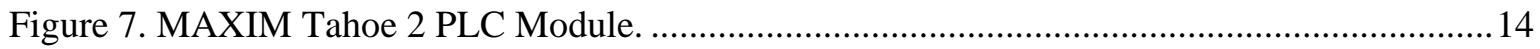

Figure 8. Setup for Throughput and Latency tests [7] ................................................................15

Figure 9. MAC / PHY Throughput Measurement. ......................................................................16

Figure 10. Texas Instruments Concerto PHY / MAC Throughput...................................................17

Figure 11. MAXIM Tahoe2+ PHY / MAC Throughput...........................................................17

Figure 12. Setup for Throughput and Latency tests [7] ............................................................. 18

Figure 13. Ariane Controls Latency Test Oscilloscope Measurement. ............................................19

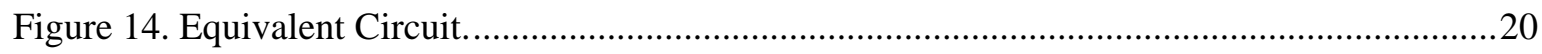

Figure 16. Setup for Pilot Signal Impairment Test [7] ...........................................................22

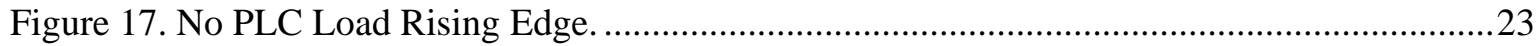

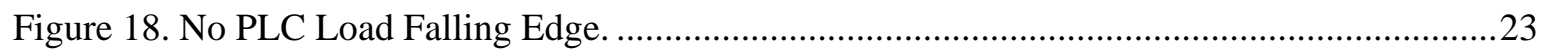

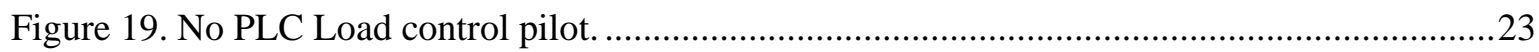

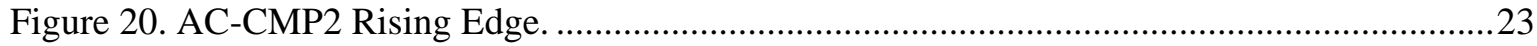

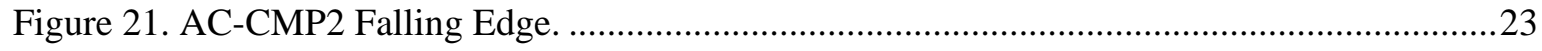

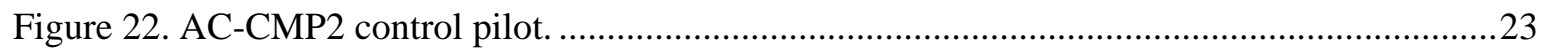

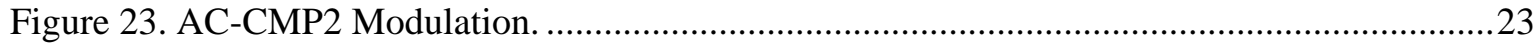

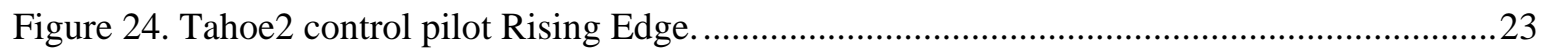

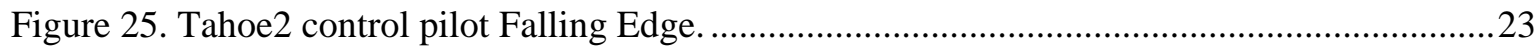

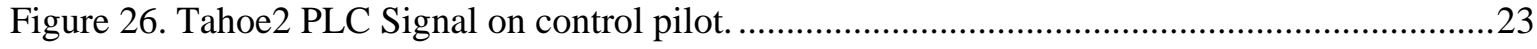

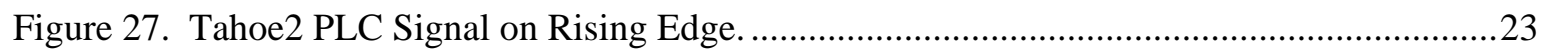

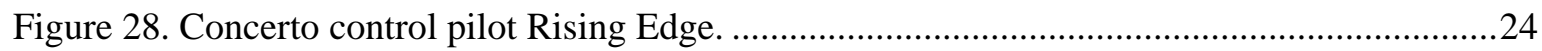

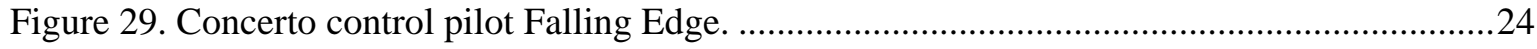

Figure 30. Concerto PLC Signal on control pilot. .....................................................................24

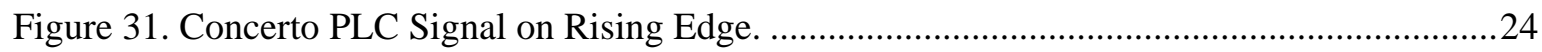

Figure 32. Lab Testing/ Field Testing Graphic.............................................................................25 


\subsection{Introduction}

The Society of Automotive Engineers is working to define communications standards for plug-in electric vehicles (PEV). In support of this effort, the J2931/1 committee tested potential technologies that could support vehicle communications. Communications for two primary purposes are being considered in this effort: (i) utility/customer communications for charge management; and (ii) off-board DC charging communications. The J2931/1 committee itemized the requirements for both forms of communications into a single test plan.

- The communications technologies described in J2931 were verified to be capable of meeting the requirements described in "S288 EV Communication Requirements Document (RD)" [9] as related to the standards J2836 [2][3][4], J2847[5][6], J2931 [7], and J2953 [8].

- The requirements and tests apply to the digital communications interface between the PEV and an external device to which it communicates. Such off-board devices may include one or more of an Electric Vehicle Support Equipment (EVSE), off-board DC charger, Home Area Network (HAN), Advanced Metering Infrastructure (AMI) meter, etc.

- To provide a safe electric charge

- To interact with energy providers in a secure manner

- To communicate information to the customer on the transaction

- This tests described in this plan are applicable to wired communications mediums only, using the J1772 charge cable. Wireless means of PEV communications are not covered in this test plan. 


\subsection{Lab and Equipment Setup}

\subsection{General Setup}

Communications testing was performed with UL-certified, UL2594 compliant, commercially available, and J1772 [1] compliant AC Level 2 EVSEs with a J1772 Cordset. The Device Under Test (DUT) is one of the communications systems being tested, consisting of two or more communicating nodes. The baseline setup is one DUT node connected to the J1772 connector, and the other DUT node terminated at an EVSE (Figure 1). The PEV receptacle was mounted in a breakout box with the mains and pilot conductors brought out to terminal strips. The PNNL Lab PEV receptacle included the capability to connect a representative commercial vehicle battery charger (A123/Hymotion L5) and used a commercial charging station (Coulomb Technologies CT2100) EVSE. When the battery charger was not connected, circuitry necessary to emulate the vehicle on-board interface was integrated into the breakout box that enabled the EVSE mains breaker to be closed. The EVSE was functional and generated the pilot Pulse Width Modulated (PWM) signal and voltages. The EVSE also had accessible connection points for the mains and pilot line signals used for connection to the DUT node. The test plan did not include measurements to be performed while a battery was being charged.

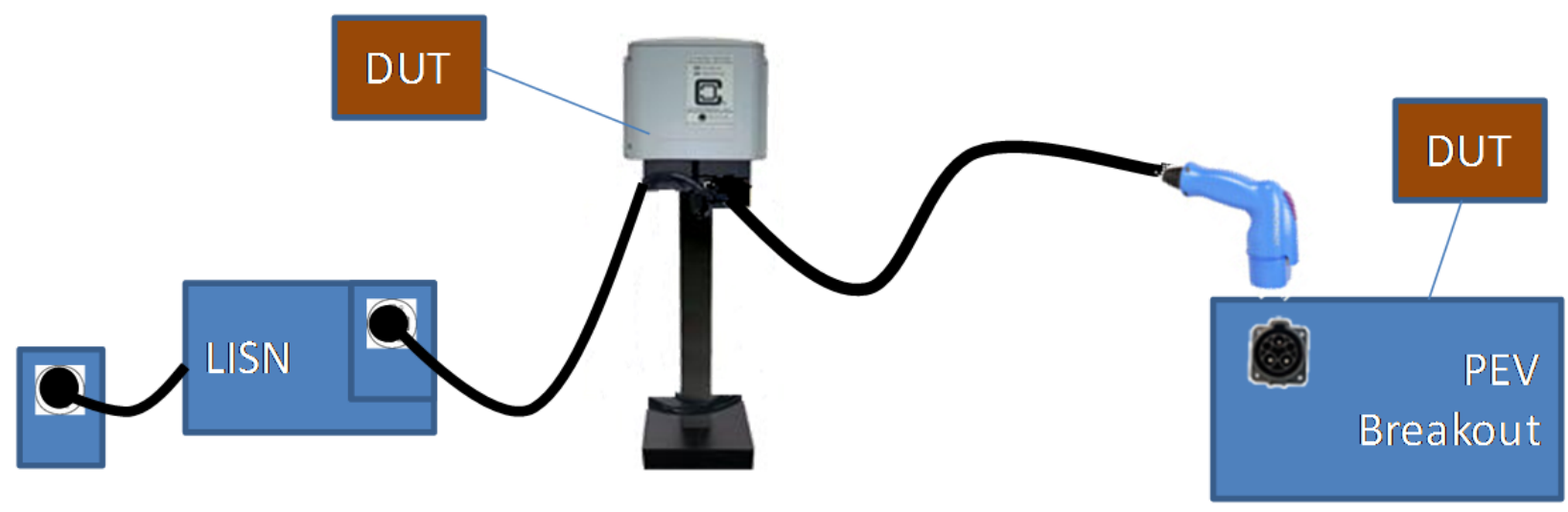

Figure 1. Baseline Lab Setup [7].

\subsection{PLC Coupling Circuits}

The PLC DUT platforms were coupled to the appropriate conductor in the cordset with a coupling circuit. The coupling circuit is dependent on whether the PLC is carried on the mains or pilot, and whether the PLC signals are in the low band (under $1 \mathrm{MHz}$ ) or high band (above $2 \mathrm{MHz}$ ). Figure 2 shows a typical coupling circuit interface for low band (G3) technology. The $1 \mathrm{nF}$ coupling capacitor shown in Figure 2 is illustrative of the coupling circuit, but each test used the components recommended by the PLC transceiver manufacturer. 


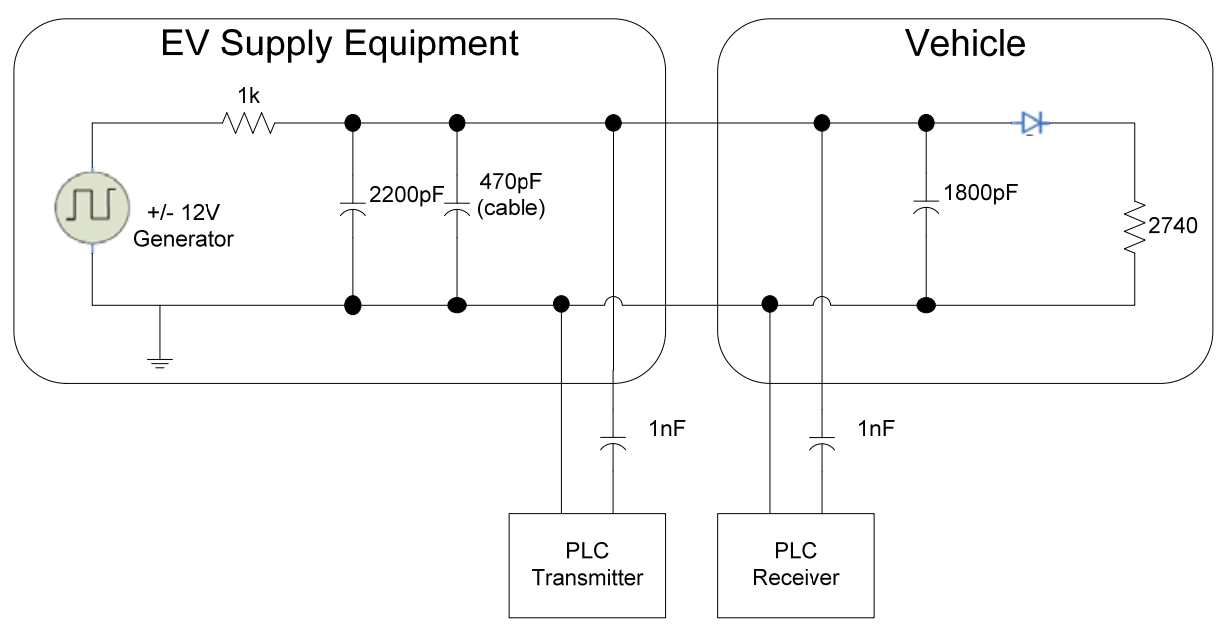

Figure 2. G3 to Pilot Coupling Circuit [7].

\subsection{Control Pilot Measurement Points}

Control pilot measurements were made at Point A and Point B as shown in Figure 3 and Figure 4.

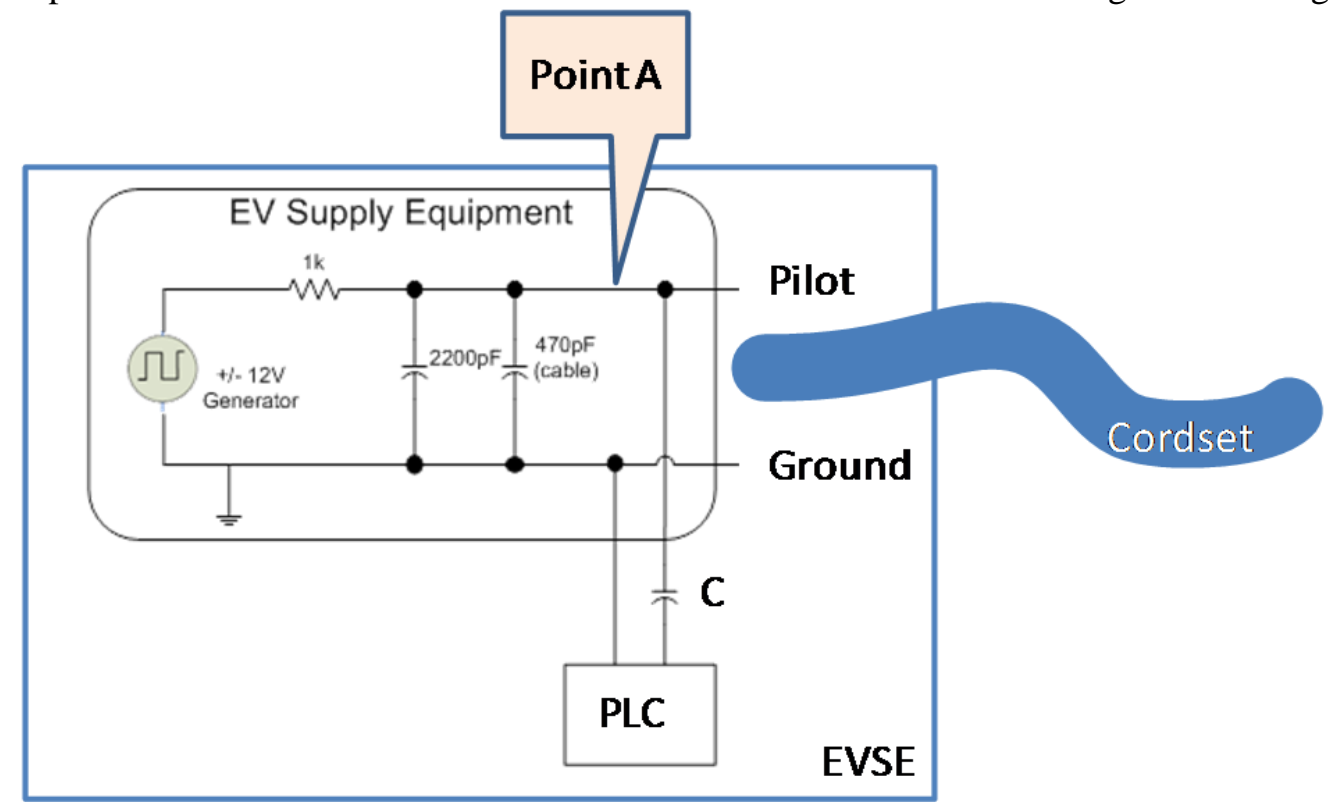

Figure 3. EVSE Pilot Measurement Point [7]. 


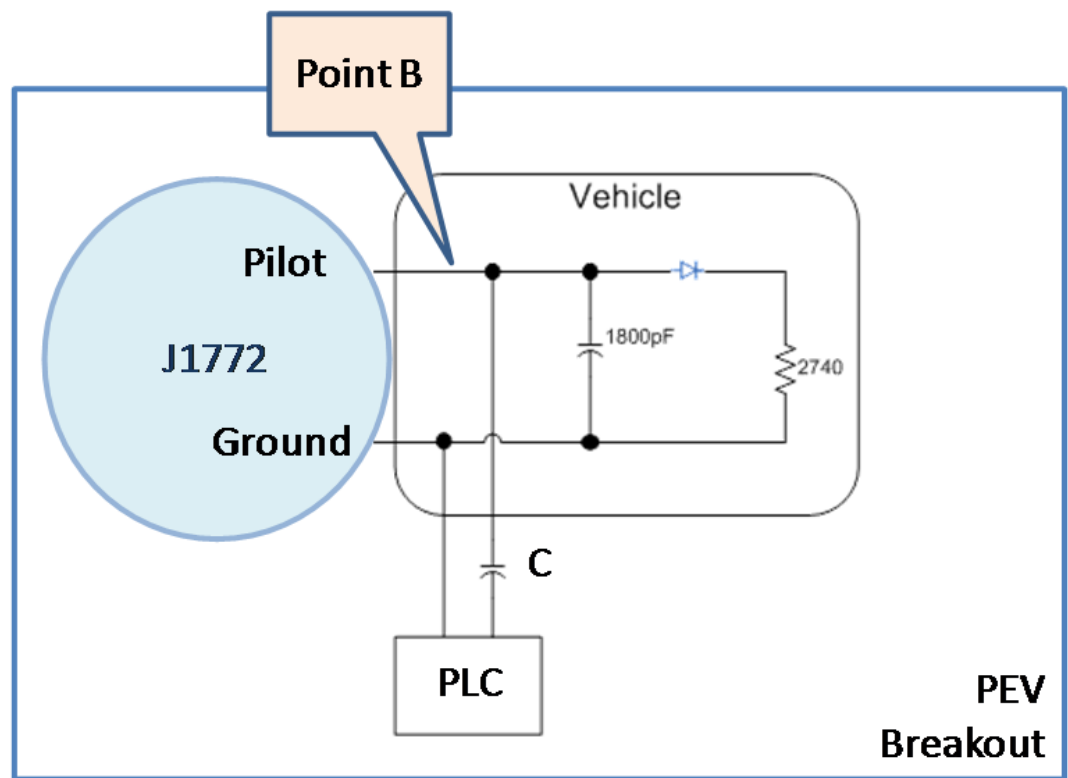

Figure 4. PEV Pilot Measurement Point [7]. 


\subsection{Products Tested}

\subsubsection{Ariane Controls AC-CPM1}

The AC-CPM1 evaluation board has four communications interfaces to enable vehicle and EVSE manufacturers to develop and test message transfers using CAN, RS-232, serial peripheral interface (SPI), or microcontroller interfaces. This product uses narrowband Frequency Shift Keying (FSK) communication for in-band signaling between PEV and EVSE. During testing, the vendor provided a firmware update to enable latency testing to be performed.

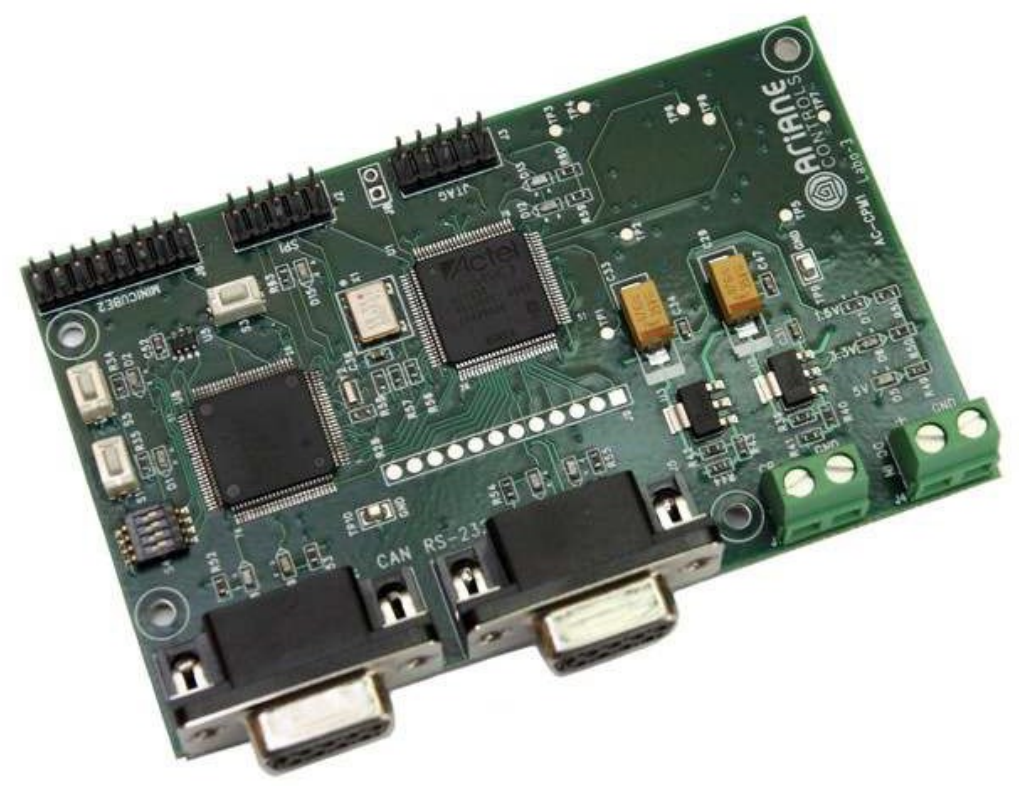

Figure 5. Ariane Controls AC-CPM1 PLC Evaluation Board.

\subsubsection{Texas Instrument Concerto}

This evaluation board integrates a TI dual-core Concerto processor with an AFE031 Integrated PLC Analog Front End chip to enable operation with either Orthogonal Frequency Division Multiplexing (OFDM) or FSK modulation. The Concerto system had SPI, RS-232, and CAN external communication interfaces. During control pilot impairment testing, the vendor supplied coupling circuit changes necessary to convert the TI Concerto prototype boards from the AC power line configuration to the control pilot configuration for throughput, latency testing, and control pilot impairment testing. 


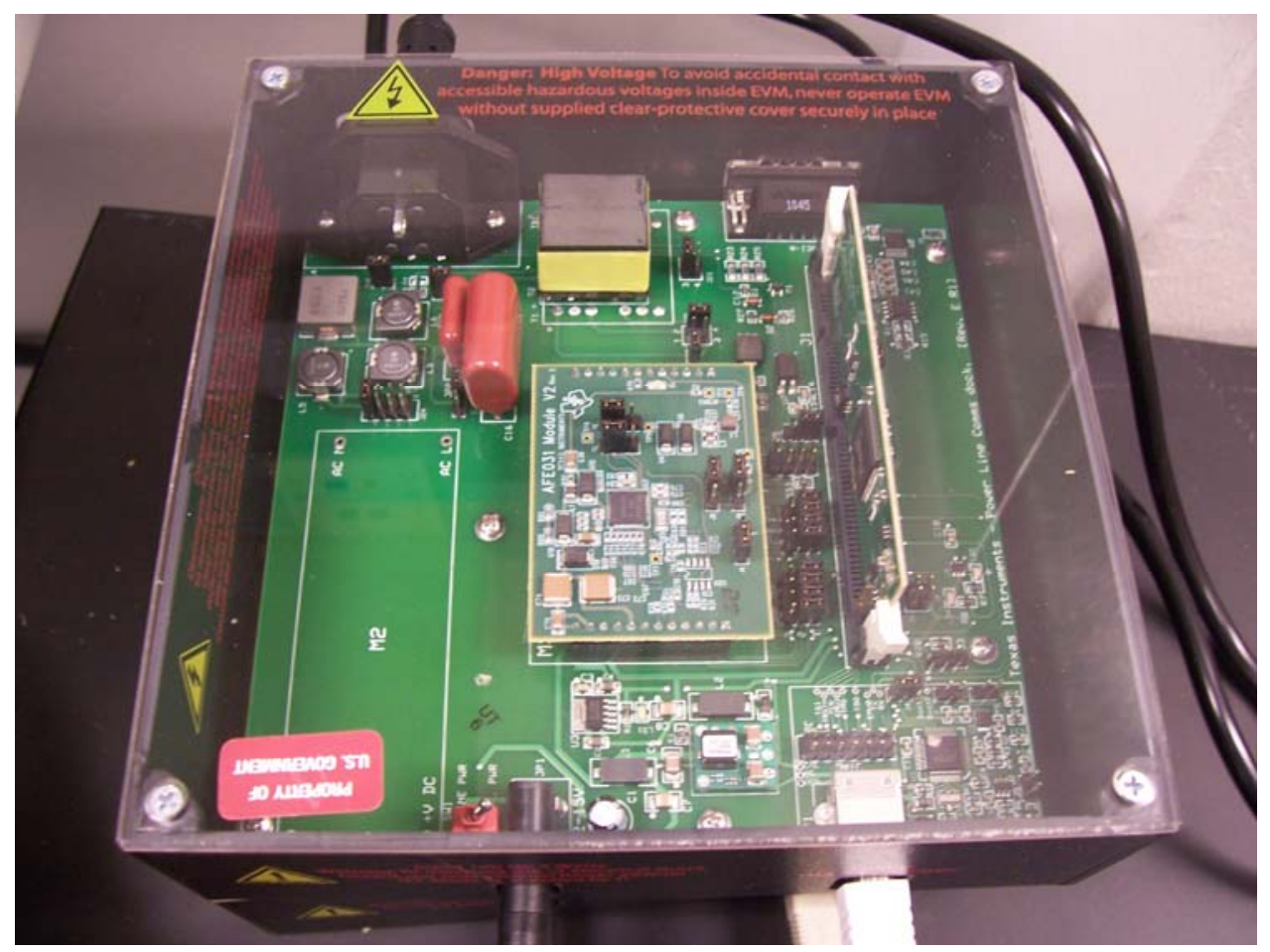

Figure 6. Texas Instruments Concerto PLC Module.

\subsubsection{MAXIM Tahoe 2}

The MAXIM Tahoe 2 incorporated IPv6 capability to the evaluation board as well as USB and a CAN interface. Minor component changes were needed to convert this board from AC power line to control pilot.

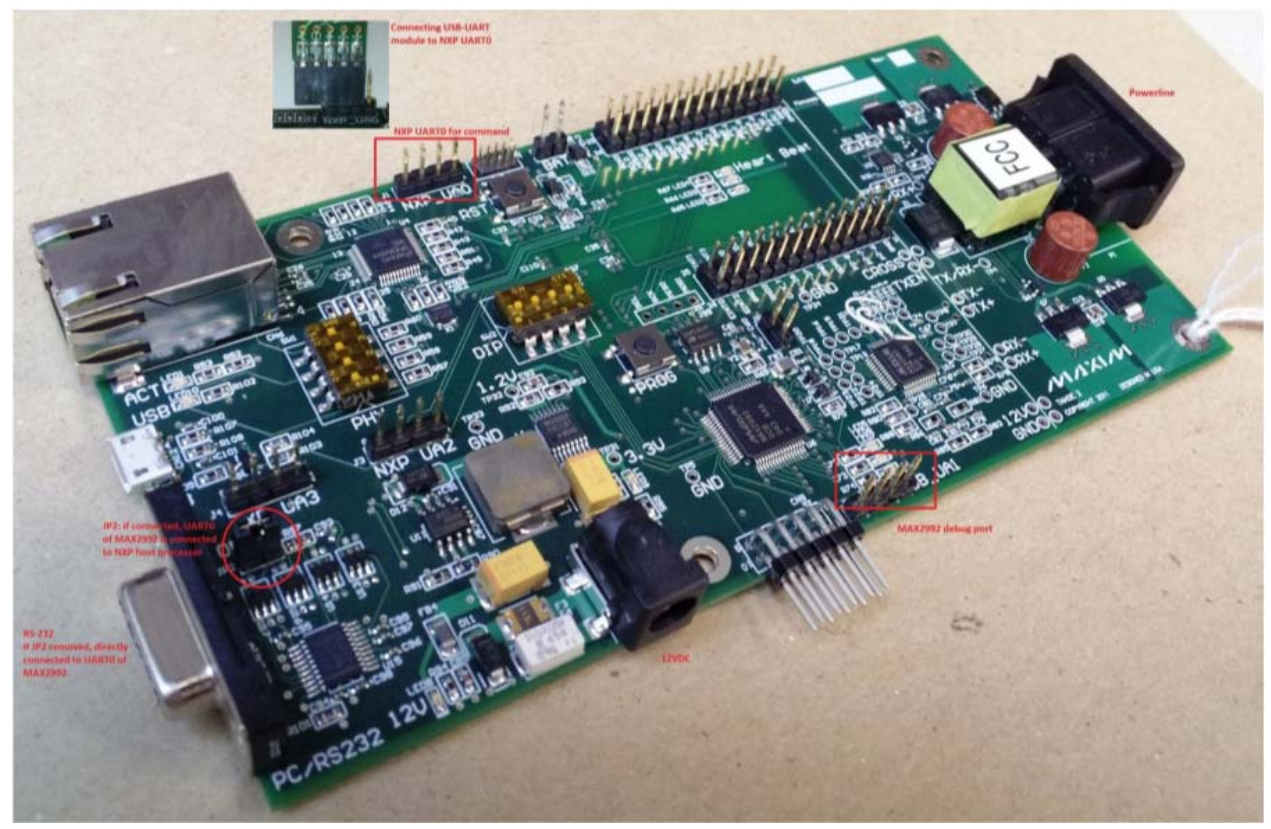

Figure 7. MAXIM Tahoe 2 PLC Module. 


\subsection{Bandwidth and Latency Test Procedures}

\subsection{Throughput Tests}

This test verifies that the DUT meets the data rate (throughput) requirements for sample message packets. The products tested were technology demonstration (evaluation) circuit boards. These tests verify the selected communication technology will support communicating messages between the PEV and the HAN, End-Use-Measurement-Device (EUMD), ESI, or other utility server or service point. These requirements include:

- The throughput at the IP layer is $100 \mathrm{kbps}$ or greater (RD.UtilComm.1) [7].

- The application data rate is $6 \mathrm{kbps}$ or greater (RD.DCComm.1) [7].

\subsubsection{Procedure}

The equipment was configured with two instances of the communications system under test (DUT) connected through the EVSE to EV link and between two computers as described in Figure 8.

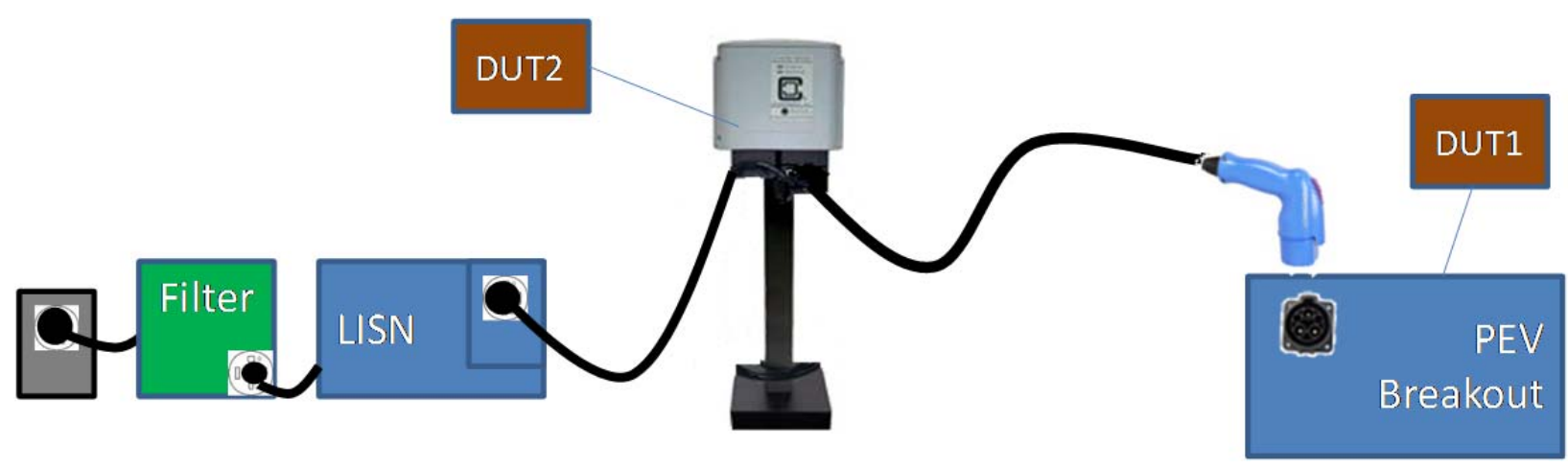

Figure 8. Setup for Throughput and Latency tests [7].

The throughput test used is similar to a DUT test where there is no feedback to the sender indicating if the message was successfully received. The test plan specified that iPerf was to be used to test network throughput. The software development time necessary to use iPerf / jPerf for testing the Texas Instruments (TI) Concerto, MAXIM Tahoe 2+, and Ariane Controls boards exactly using the J2931/1 test procedure was not available. An alternative throughput performance method was devised. Since the throughput communications test is a one-way test from source to destination and the data transfer signals are readily observable and measureable using an oscilloscope, a data source faster than the testing specification and that sends a known number of bytes can be used. The throughput rate is calculated by dividing the number of bytes transmitted by the transmission time (see Figure 9). In order to ensure that evaluation board-related delays were taken into account (i.e., buffering, block transfers, etc.), a transmission time of several seconds was used.

For the Ariane Controls AC-CPM1 and TI Concerto, the RS-232 serial interface operated at 115.2kbps was used to test throughput. The MAXIM Tahoe 2+ used a USB serial interface. Throughput 
testing requires that the DUT product initially be configured and then execute data transfers to measure throughput. The most straightforward method of collection was to use the TI Graphical User Interface (GUI) and the MAXIM PLC Connect GUI to configure and execute known length data transfers using the serial interface.

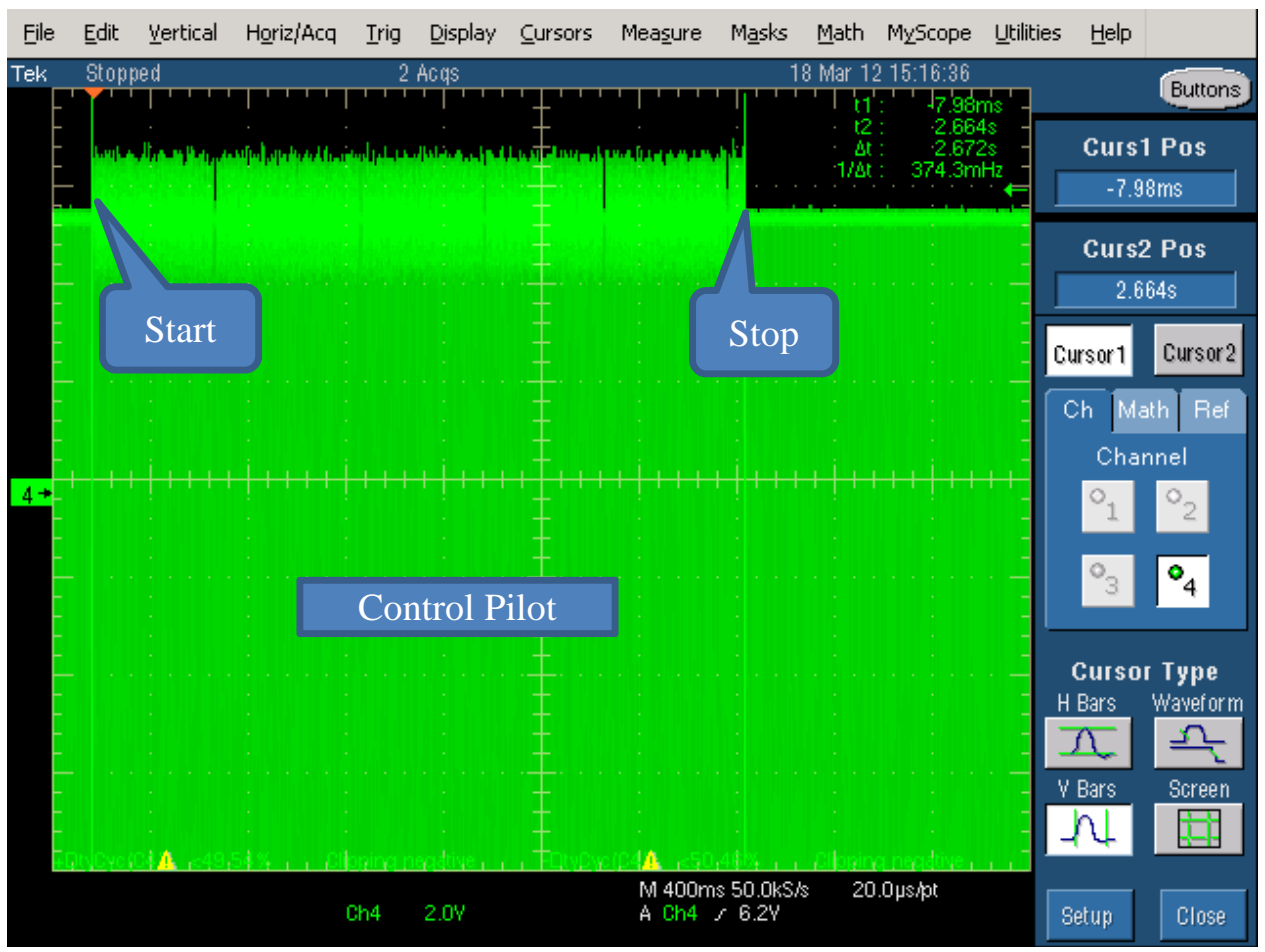

Figure 9. MAC / PHY Throughput Measurement.

\subsubsection{Test Limit}

Test RD.UtilComm.1

TestRD.DCComm.1

$100 \mathrm{kbps}$

$6 \mathrm{kbps}$

\subsubsection{Test Matrix}

The throughput tests were repeated for each DUT communications technology.

\begin{tabular}{|l|c|c|c|}
\hline G3 on Pilot & Throughput Value & $\begin{array}{c}\text { UtilComm.1 } \\
\text { Pass/Fail }\end{array}$ & $\begin{array}{c}\text { DCComm.1 } \\
\text { Pass/Fail }\end{array}$ \\
\hline MAXIM Tahoe 2+ on Pilot & $109^{(2)} \mathrm{kbps}$ & Pass & Pass \\
\hline Texas Instruments Concerto & $105^{(3)} \mathrm{kbps}$ & Pass & Pass \\
\hline Ariane Controls FSK on Pilot & $39^{(1)(4)} \mathrm{kbps}$ & Fail & Pass \\
\hline
\end{tabular}

(1) Ariane Controls AC-CPM1 MAC/PHY throughput rate was determined by measuring the transfer time of a 1000 byte packet sent via serial port using hardware flow control.

${ }^{(2)}$ MAXIM Tahoe 2+ MAC/PHY throughput rate was determined by measuring the average transfer time of 50 to 1280-byte packets sent via serial port using the MAXIM G3 PLC Connect GUI (see Figure 11). 
(3) TI Concerto MAC/PHY throughput rate was determined by measuring the average transfer time of 25 to 236-byte packets sent via serial port using the TI GUI (see Figure 10).

(4) The Ariane Controls oscilloscope traces showed that increasing the baud rate or implementing an SPI could reduce this bottleneck.

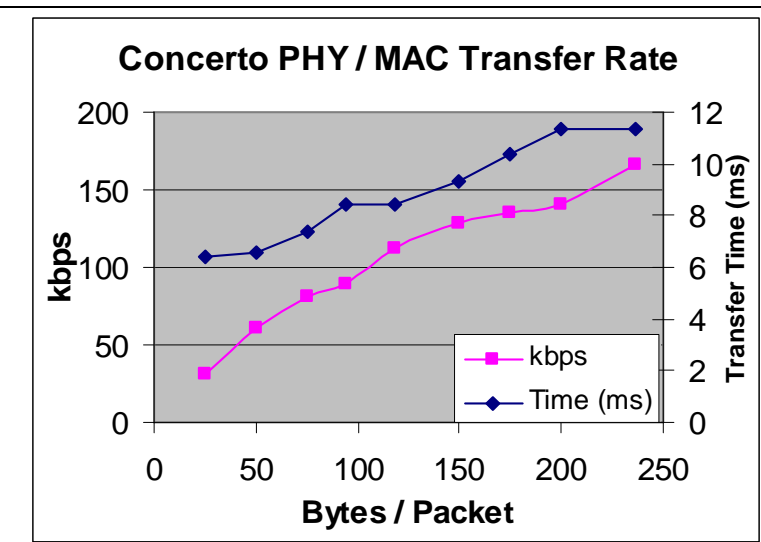

Figure 10. Texas Instruments Concerto PHY / MAC Throughput.

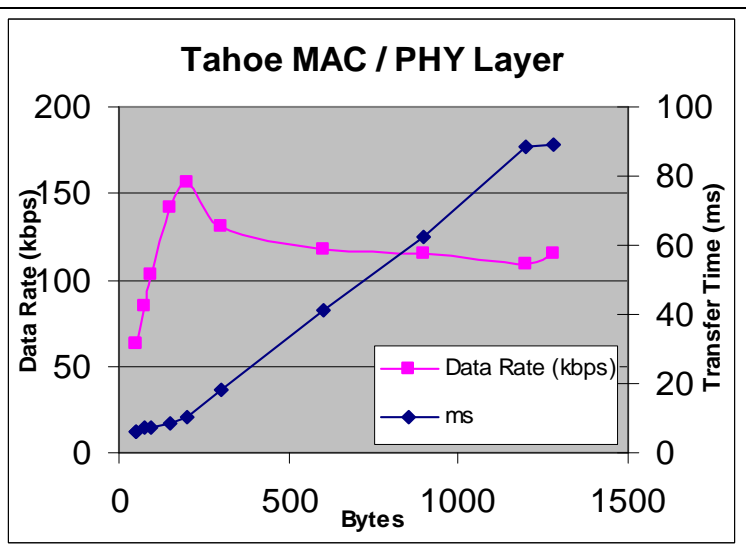

Figure 11. MAXIM Tahoe2+ PHY / MAC Throughput.

\subsubsection{Latency Tests}

This test verifies that the DUT meets the round trip time (latency) requirements for sample message packets. These tests verify the selected communication technology will support communicating messages between the PEV and the HAN, EUMD, ESI, or other utility server or service point. These requirements include:

- The round trip message latency is 25ms max (RD.DCComm.2) [7].

- The utility message latency is a maximum of 15 minutes (RD.UtilComm.2) [7].

\subsubsection{Procedure}

The equipment was configured with two instances of the communications system under test (DUT) connected through the EVSE to EV link and between two computers as described in Figure 12. 


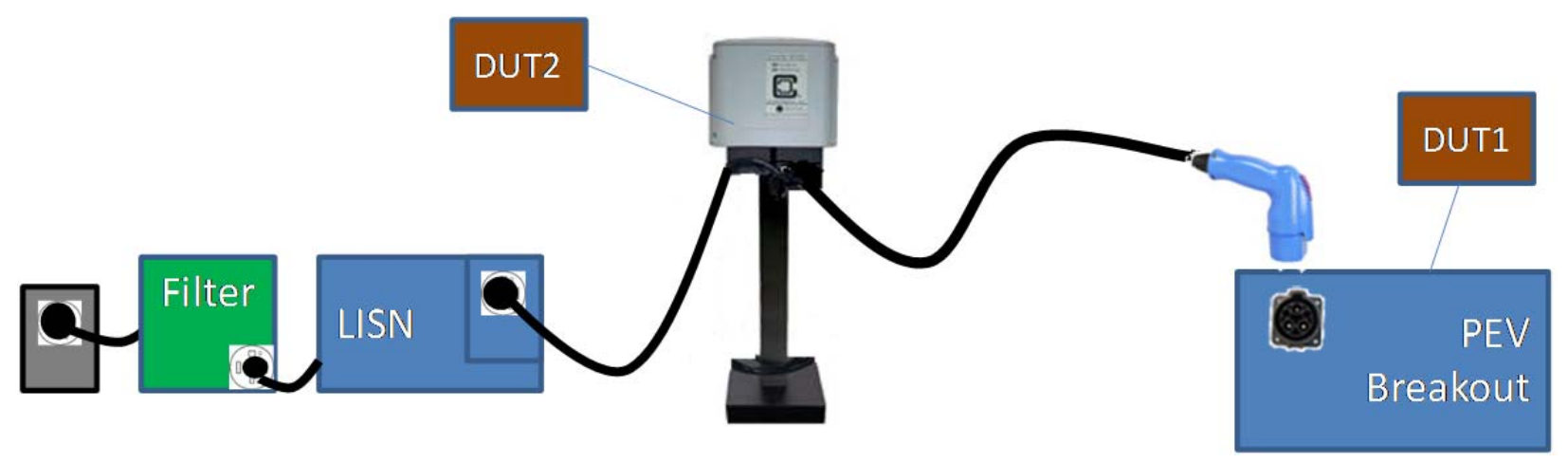

Figure 12. Setup for Throughput and Latency tests [7].

The software development time necessary to implement the iPv6 PING command functionality was not available. However, an alternative latency measurement method was devised. WireShark measurements of an iPv6 PING packet length was 94 bytes. Figure 13 shows the latency measurement of a 94-byte packet using an oscilloscope for the Ariane Controls AC-CPM1 board. The latency measurement for the TI Concerto and MAXIM Tahoe 2+ could only be estimated using twice the oneway transfer time shown on the Figure 10 and Figure 11 graphs for a 100-byte packet. These products require an external controller to perform the required two-way measurement. The IPv6 to RS232 controller was not readily available.

\subsubsection{Test Limit}

Test RD.UtilComm.2 900,000 mS

Test RD.DCComm.1 $25 \mathrm{mS}$

\subsubsection{Test Matrix}

Repeat tests for each DUT communications technology.

\begin{tabular}{|l|c|c|c|}
\hline G3 on Pilot & Latency Value & $\begin{array}{c}\text { UtilComm.2 } \\
\text { Pass/Fail }\end{array}$ & $\begin{array}{c}\text { DCComm.1 } \\
\text { Pass/Fail }\end{array}$ \\
\hline MAXIM Tahoe 2+ & 20 ms est. $^{(1)}$ & Pass $^{(1)}$ & Pass $^{(\mathbf{1})}$ \\
\hline Texas Instruments Concerto & 12 ms est. $^{(1)}$ & Pass $^{(\mathbf{1})}$ & Pass $^{(\mathbf{1})}$ \\
\hline Ariane Controls & $47.3 \mathrm{~ms}^{(2)}$ & Pass $^{(2)}$ & Fail \\
\hline
\end{tabular}

(1) There was not a straightforward way to directly measure latency in the available time using these evaluation boards, however using Figure 10 for the TI Concerto an estimated latency for a 100-byte packet would be less than 12 milliseconds and using Figure 11 for the MAXIM Tahoe 2+ an estimated latency for a 100-byte packet would be less than 20 milliseconds. Note: the transfer time value in the graph must be doubled for the round trip latency time measurement.

(2) The Ariane Controls oscilloscope traces showed that increasing the baud rate or implementing an SPI could reduce this bottleneck (see Figure 13). 


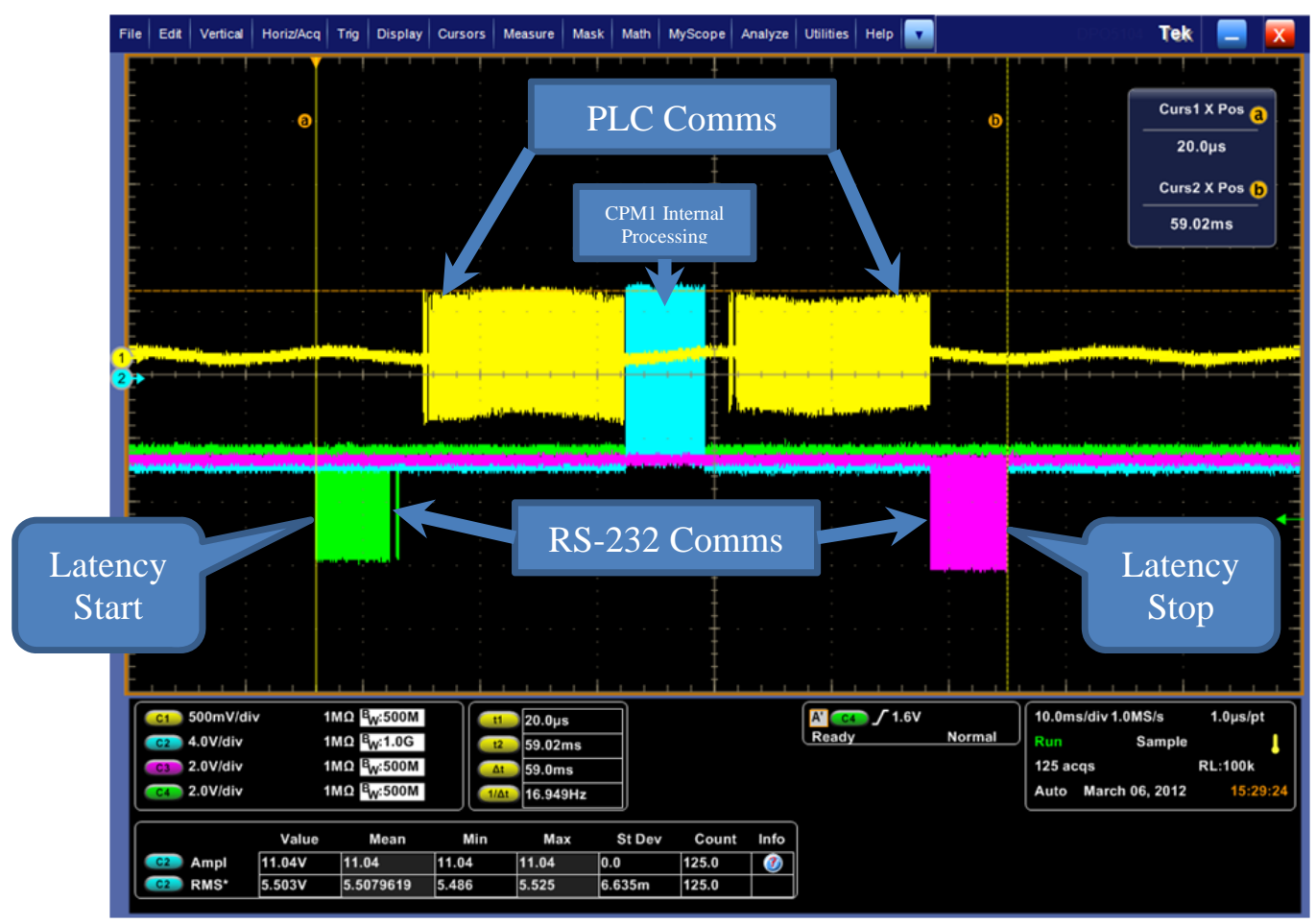

Figure 13. Ariane Controls Latency Test Oscilloscope Measurement. 


\subsection{Control Pilot Impairment Test}

\subsection{Impairment Tests}

This test measures how the DUT affects the control pilot signal both when the DUT was ON and when it was OFF. The pilot signal impairment test verifies that the selected PLC solution can interoperate with all EVSEs and EVs (RD.App.12) [7] and the communication solution must not interfere with operation of existing legacy devices compliant with the current (2010) release of $\mathrm{J} 1772^{\mathrm{TM}}$ (RD.App.13) [7].

\subsubsection{Procedure}

This test verifies that the connection of the PLC systems to the charge cable do not adversely affect the $1 \mathrm{kHz}$ PWM signal on the pilot wire.

\subsubsection{Performance Requirements}

\section{Rise time / Fall time of PWM signal}

The SAE J1772 ${ }^{\mathrm{TM}}$ and the IEC 61851-1 annex A specify the rise/fall times at $2 \mu$ s maximum on the EVSE side, without any specification on the EV side.

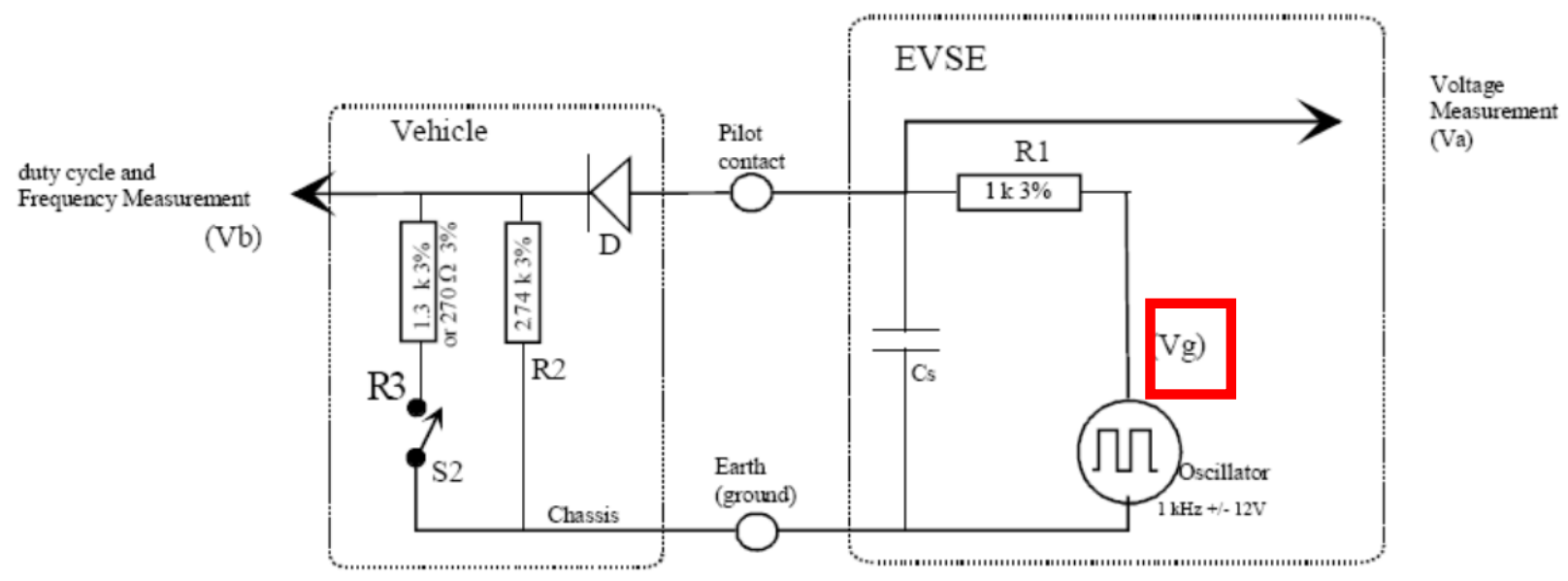

Figure 14. Equivalent Circuit.

It is required to perform measurements without PLC and with PLC to quantify precisely the impact. The way to measure the rise time and the fall time is described in the SAE J1772 ${ }^{\mathrm{TM}}$ or the IEC 61851-1.

\subsubsection{Pulse width (Duty Cycle) of the PWM signal}

Since the duty cycle codes the maximum current available, it is crucial that the PLC technology does not modify this value. 
The SAE J1772 ${ }^{\mathrm{TM}}$ and IEC 61851-1 annex A specify that the generator injects the PWM signal with a frequency of $1000 \mathrm{~Hz}$ and a pulse width tolerance of $+/-25 \mu$ s at the EVSE. No limits are specified on the EV side in this document.

It is required to perform measurements without PLC and with PLC communications to quantify precisely the impact.

During this test, it is also required to measure the spectrum of the signal in the frequency band used by the PLC technology.

The way to measure the duty cycle is described in the SAE J1772 ${ }^{\mathrm{TM}}$ or the IEC 61851-1.

\subsubsection{Amplitude of the PWM signal}

The SAE J1772 ${ }^{\text {TM }}$ and IEC 61851-1 annex A specify values for the different states, with a tolerance of $+/-1 \mathrm{~V}$ max for the whole system.

For the signal injection on the pilot line, the PLC boards inject around 1Volt peak-to-peak (VPP). From there, the voltage should be decreased by steps of $20 \%$ to find the limit where the communication is lost. The way to find the limit can vary according to the software tool used to manage PLC boards.

At each stage, it is required to measure all the following parameters on the affected circuit:

- Rise time

- Fall time

- Amplitude

- Peak-to-peak values of the whole signal

- Peak-to-peak values of the PLC signal during the positive state of the signal

- Duty cycle

- Frequency

- Screenshot of the waveform

It is required to perform measurements without PLC and with PLC communications to precisely quantify the impact.

\subsection{Procedure}

Configure the equipment as shown in Figure 14. Measurements of the rise/fall time, duty cycle and amplitude of the Pilot PWM waveform should be done with an oscilloscope. 


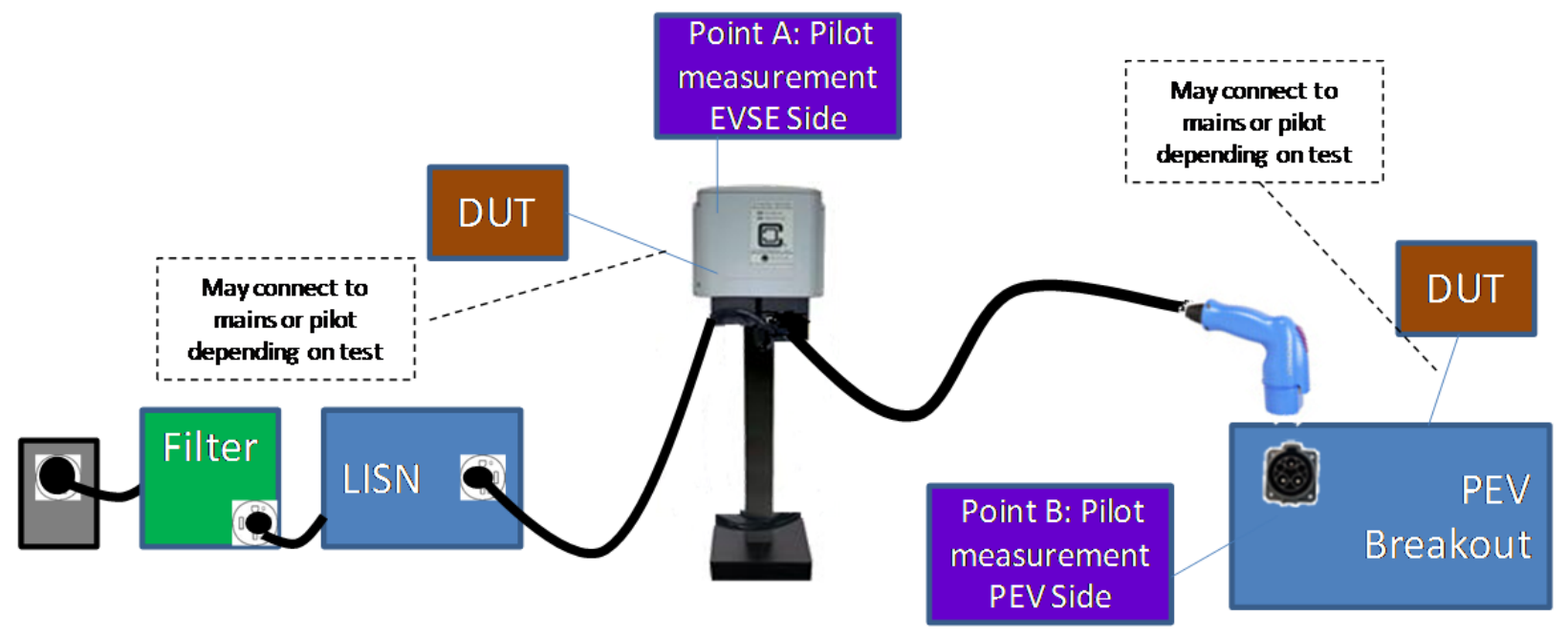

Figure 15. Setup for Pilot Signal Impairment Test [7].

Measure the Rise/Fall Time, duty cycle, and amplitude of the PWM pilot waveform and verify that the values meet the requirements. Repeat the tests with and without active PLC signals on the control pilot, according to the test matrix below.

4.2.1.1 Test Matrix Summary

\begin{tabular}{|c|c|c|c|c|}
\hline Technology Tested & PLC State & $\begin{array}{c}\text { Pilot PWM } \\
\text { Measurement }\end{array}$ & $\begin{array}{c}\text { Specification } \\
\text { (J2931/1 Sec. } \\
\text { 6.5.4.1) } \\
\end{array}$ & Results \\
\hline \multirow{6}{*}{$\begin{array}{l}\text { Ariane Controls AC- } \\
\text { CPM1 on Pilot }\end{array}$} & \multirow{3}{*}{$\begin{array}{l}\text { PLC powered } \\
\text { and active }\end{array}$} & Rise/Fall Time & $2 \mu \mathrm{s}$ maximum & Pass \\
\hline & & Duty Cycle & $+/-25 \mu \mathrm{s}$ & Pass \\
\hline & & Amplitude & $+/-1 \mathrm{~V} \max$ & Pass \\
\hline & \multirow{3}{*}{$\begin{array}{l}\text { PLC } \\
\text { unpowered }\end{array}$} & Rise/Fall Time & $2 \mu \mathrm{s}$ maximum & Pass \\
\hline & & Duty Cycle & $+/-25 \mu \mathrm{s}$ & Pass \\
\hline & & Amplitude & $+/-1 \mathrm{~V} \max$ & Pass \\
\hline \multirow{6}{*}{$\begin{array}{l}\text { Texas Instruments } \\
\text { Concerto G3 on } \\
\text { Pilot }\end{array}$} & \multirow{3}{*}{$\begin{array}{l}\text { PLC powered } \\
\text { and active }\end{array}$} & Rise/Fall Time & $2 \mu \mathrm{s}$ maximum & Pass \\
\hline & & Duty Cycle & $+/-25 \mu \mathrm{s}$ & Pass \\
\hline & & Amplitude & $+/-1 \mathrm{~V} \max$ & Pass \\
\hline & \multirow{3}{*}{$\begin{array}{l}\text { PLC } \\
\text { unpowered }\end{array}$} & Rise/Fall Time & $2 \mu \mathrm{s}$ maximum & Pass \\
\hline & & Duty Cycle & $+/-25 \mu \mathrm{s}$ & Pass \\
\hline & & Amplitude & $+/-1 \mathrm{~V} \max$ & Pass \\
\hline \multirow{6}{*}{$\begin{array}{l}\text { MAXIM Tahoe } 2+ \\
\text { on Pilot }\end{array}$} & \multirow{3}{*}{$\begin{array}{l}\text { PLC powered } \\
\text { and active }\end{array}$} & Rise/Fall Time & $2 \mu \mathrm{s}$ maximum & Pass \\
\hline & & Duty Cycle & $+/-25 \mu \mathrm{s}$ & Pass \\
\hline & & Amplitude & $+/-1 \mathrm{~V} \max$ & Pass \\
\hline & \multirow{3}{*}{$\begin{array}{l}\text { PLC } \\
\text { unpowered }\end{array}$} & Rise/Fall Time & $2 \mu \mathrm{s}$ maximum & Pass \\
\hline & & Duty Cycle & $+/-25 \mu \mathrm{s}$ & Pass \\
\hline & & Amplitude & $+/-1 \mathrm{~V} \max$ & Pass \\
\hline
\end{tabular}

The products tested: Ariane Controls AC-CPM1, MAXIM Tahoe 2+, and TI Concerto all passed Control Pilot Impairment Test. 


\subsubsection{Control Pilot Impairment Test Matrix Results}

\begin{tabular}{|l|c|c|c|c|c|c|}
\hline Product & Rise Time & Fall Time & Amplitude & PLC $_{\mathrm{pp}}$ & Duty Cycle & Frequency \\
\hline Specification & $<2 \mu \mathrm{s}$ & $<2 \mu \mathrm{s}$ & $\pm 12 \mathrm{~V}$ & $1.0 \mathrm{~V}_{\mathrm{pp}}$ & $50 \% \pm 2.5 \%$ & $\pm 20 \mathrm{~Hz}$ \\
\hline None & $2.8 \mu \mathrm{s}$ & $3.7 \mu \mathrm{s}$ & $\pm 12 \mathrm{~V}$ & ----- & $50.01 \%$ & $1000 \mathrm{~Hz}$ \\
\hline AC-CPM2 & $36 \mu \mathrm{s}$ & $44 \mu \mathrm{s}$ & $5.6 \mathrm{~V}$ & $0.74 \mathrm{~V}_{\mathrm{pp}}$ & $50 \%$ & $1000 \mathrm{~Hz}$ \\
\hline Tahoe2++ & $5.3 \mu \mathrm{s}$ & $7.8 \mu \mathrm{s}$ & $5.7 \mathrm{~V}$ & $1.24 \mathrm{~V}_{\mathrm{pp}}$ & $50.03 \%$ & $1000 \mathrm{~Hz}$ \\
\hline Concerto & $66.4 \mu \mathrm{s}$ & $90.4 \mu \mathrm{s}$ & $5.7 \mathrm{~V}$ & $1.32 \mathrm{~V}_{\mathrm{pp}}$ & $50.34 \%$ & $1000 \mathrm{~Hz}$ \\
\hline
\end{tabular}

Note 1: All measurements were made on the control pilot line. The $2 \mu$ specification applies to the upstream side of the $1 \mathrm{kOhm}$ source resistor, R1.

Control Pilot Impairment Oscilloscope Screenshots - No PLC Device Connected

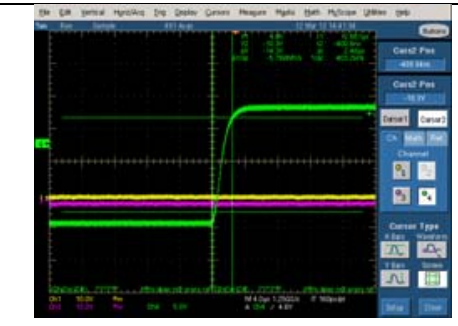

Figure 16. No PLC Load Rising Edge.

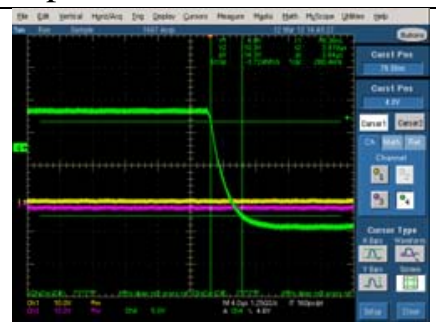

Figure 17. No PLC Load Falling Edge.

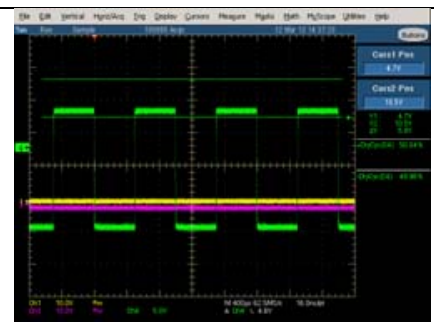

Figure 18. No PLC Load control pilot.

Ariane Controls Powered Control Pilot Impairment Oscilloscope Screen Shots

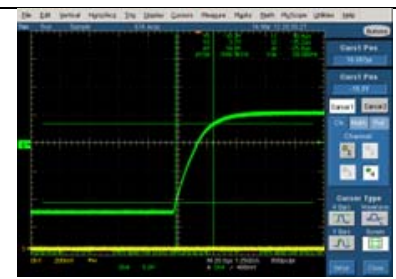

Figure 19. AC-CMP2 Rising Edge.

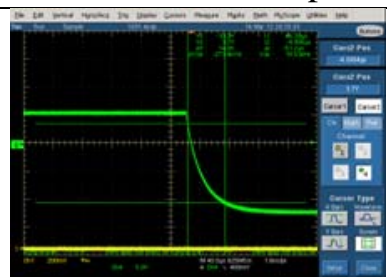

Figure 20. AC-CMP2 Falling Edge.

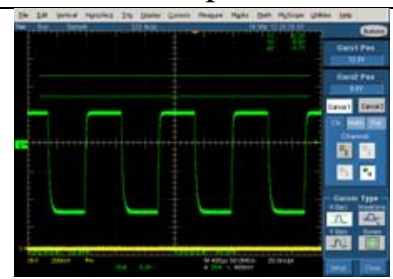

Figure 21. AC-CMP2 control pilot.

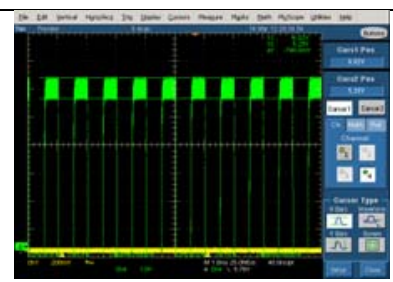

Figure 22. AC-CMP2 Modulation.

MAXIM Tahoe2++ Powered Control Pilot Impairment Oscilloscope Screen Shots

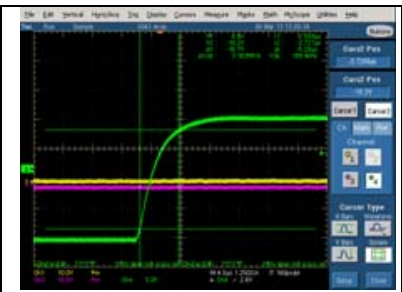

Figure 23. Tahoe2 control pilot Rising Edge.

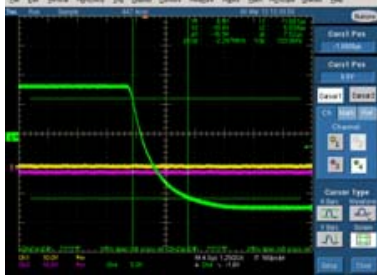

Figure 24. Tahoe2 control pilot Falling Edge.

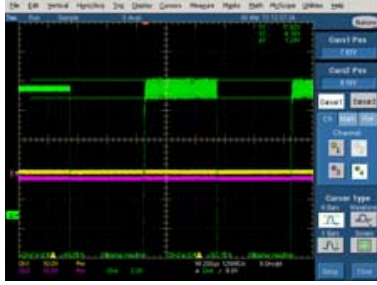

Figure 25. Tahoe2 PLC Signal on control pilot.

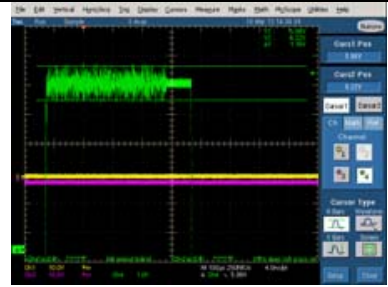

Figure 26. Tahoe2 PLC Signal on Rising Edge. 
TI Concerto Powered Control Pilot Impairment Oscilloscope Screen Shots

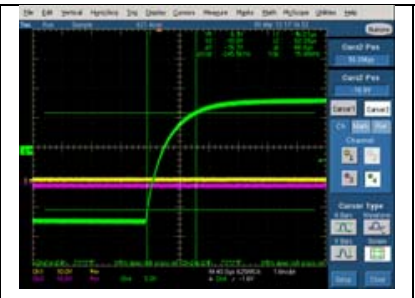

Figure 27. Concerto control pilot Rising Edge.

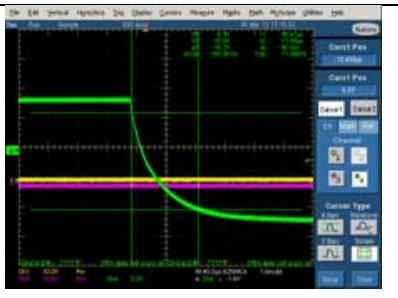

Figure 28. Concerto control pilot Falling Edge.

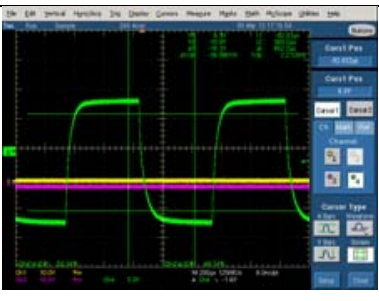

Figure 29. Concerto PLC Signal on control pilot.

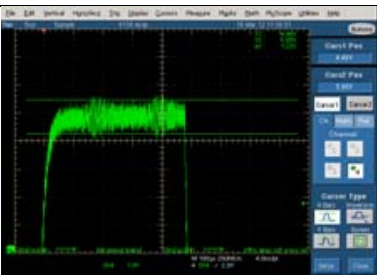

Figure 30. Concerto PLC Signal on Rising Edge. 


\subsection{Conclusions}

Narrowband PLC communications prototype products from TI Concerto and MAXIM (Tahoe 2) demonstrated that they could meet the throughput, latency, and control pilot impairment test requirements specified by the SAE J2931/1 Test Plan. Although no PLC communication technology met all requirements of the SAE J2931/1 Test Plan, the SAE J2931/1 committee chose the broadband HPGP technology which demonstrated the potential for higher data rate performance than the narrowband PLC technology.

The red circle shown in Figure 32 below shows the extent of the J2931/1 Lab testing within a complete single unit installation. The HPGP technology must be integrated into a system that includes communication with the OEM's CAN bus, DC charger messages, SEP2.0 messages, and communication with the HAN/Utility. PNNL plans to work with the SAE committee to continue the system level testing with the revisions to SAE J2847/1 planned for FY13.

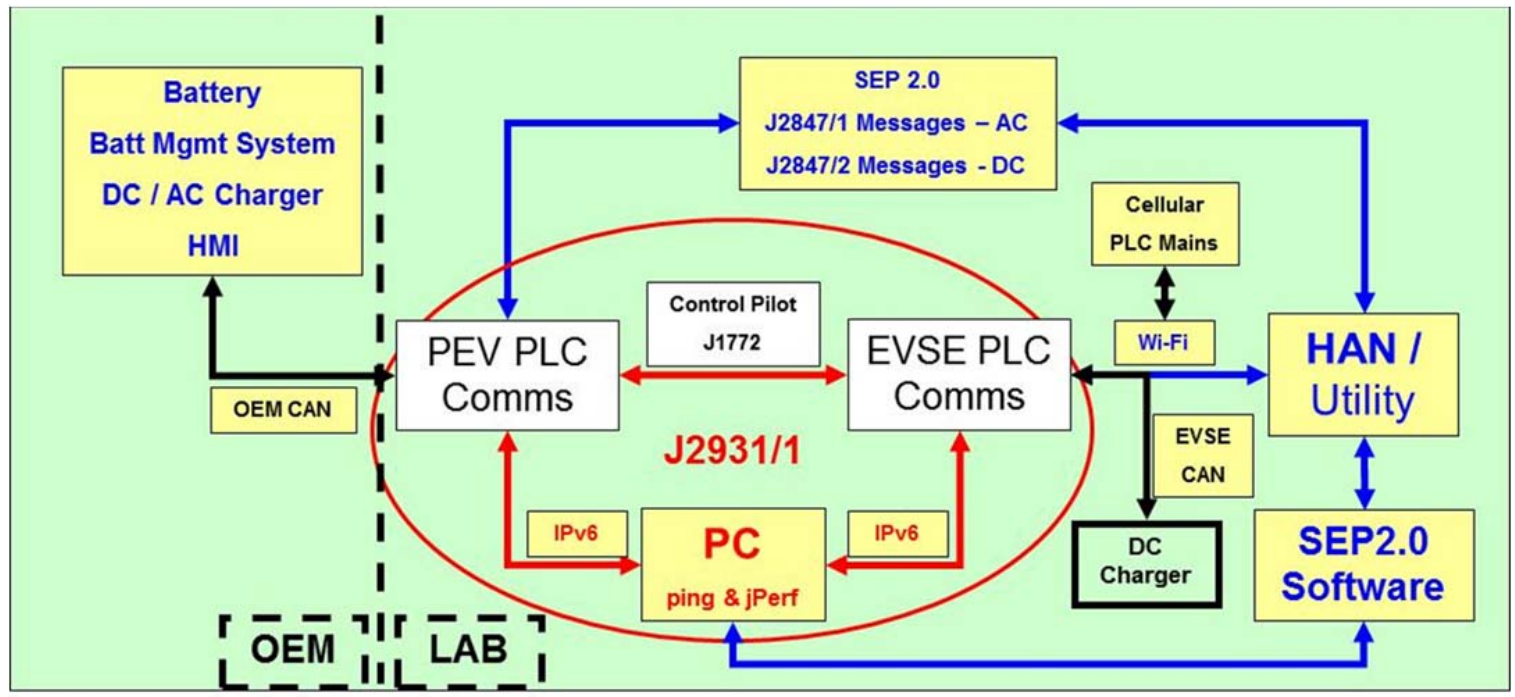

Red - J2931/1 Testing - Done

Blue - Proposed Next Phase

OEMs may need IPv6 to CAN translation module

Field Testing Requirements Labs / OEM's jointly involved in field testing will minimize compatibility issues and maximize testing impact.

Testing specifications / methods clearly defined

Figure 31. Lab Testing/ Field Testing Graphic. 


\subsection{References}

[1] SAE J1772 ${ }^{\mathrm{TM}}$ SAE Electric Vehicle and Plug-in Hybrid Electric Vehicle Conductive Charge Coupler. (Surface Vehicle Recommended Practice). SAE International, Warrendale, PA.

[2] SAE J2836/1 ${ }^{\mathrm{TM}}$ Use Cases for Communication between Plug-in Vehicles and the Utility Grid. (Surface Vehicle Recommended Practice). SAE International, Warrendale, PA.

[3] SAE J2836/2 ${ }^{\text {TM }}$ Use Cases for Communication between Plug-in Vehicles and the Supply Equipment (EVSE) (Surface Vehicle Information Report). SAE International, Warrendale, PA.

[4] J2836/3 Use Cases for Communication between Plug-in Vehicles and the Utility Grid for Reverse Power Flow (Surface Vehicle Information Report).

[5] SAE J2847/1 ${ }^{\text {TM }}$ Communication between Plug-in Vehicles and the Utility Grid. (Surface Vehicle Recommended Practice). SAE International, Warrendale, PA.

[6] J2847/2 Communication between Plug-in Vehicles and the Supply Equipment (EVSE) (Surface Vehicle Recommended Practice).

[7] T. Godfrey, SAE J2931/1 PLC Communication Test Plan, September 2011. Electric Power Research Institute, Palo Alto, CA.

[8] J2953 Plug-In Electric Vehicle (PEV) Interoperability with Electric Vehicle Supply Equipment (EVSE) (Surface Vehicle Recommended Practice).

[9] EV Communication Requirements Document (RD), Draft Version 0.10. SAE J2836, J3847, J2931 \& J2953 Task Force, May 27, 2011. 


\section{Distribution}

No. of

$\underline{\text { Copies }}$

\# Lee Slezak

United States Department of Energy,

Office of Vehicle Technologies

1000 Independence Ave, OE-10

Washington, DC 20585

\# Dan Ton

United States Department of Energy,

Office of Electricity

1000 Independence Ave, OE-10

Washington, DC 20585 


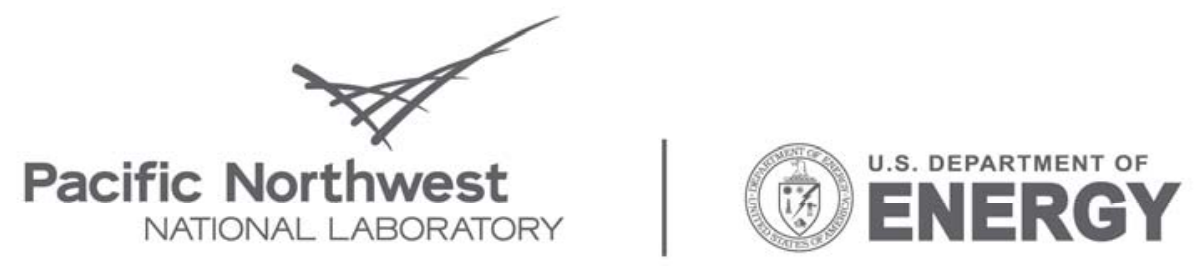

Proudly Operated by Battelle Since 1965

902 Battelle Boulevard

P.O. Box 999

Richland, WA 99352

1-888-375-PNNL (7665)

www.pnl.gov 